\title{
Unique Cyst in a 22-Year-Old Man
}

Alberto Ramos-Garibay, MD, Gisela Navarrete-Franco, MD, Sandra Gutiérrez-Zambrano, MD, and Mónica Olivia Rivera Ramírez, MD

FIGURE 1. Cyst with a normal epidermis surface $(H \& E \times 4)$.
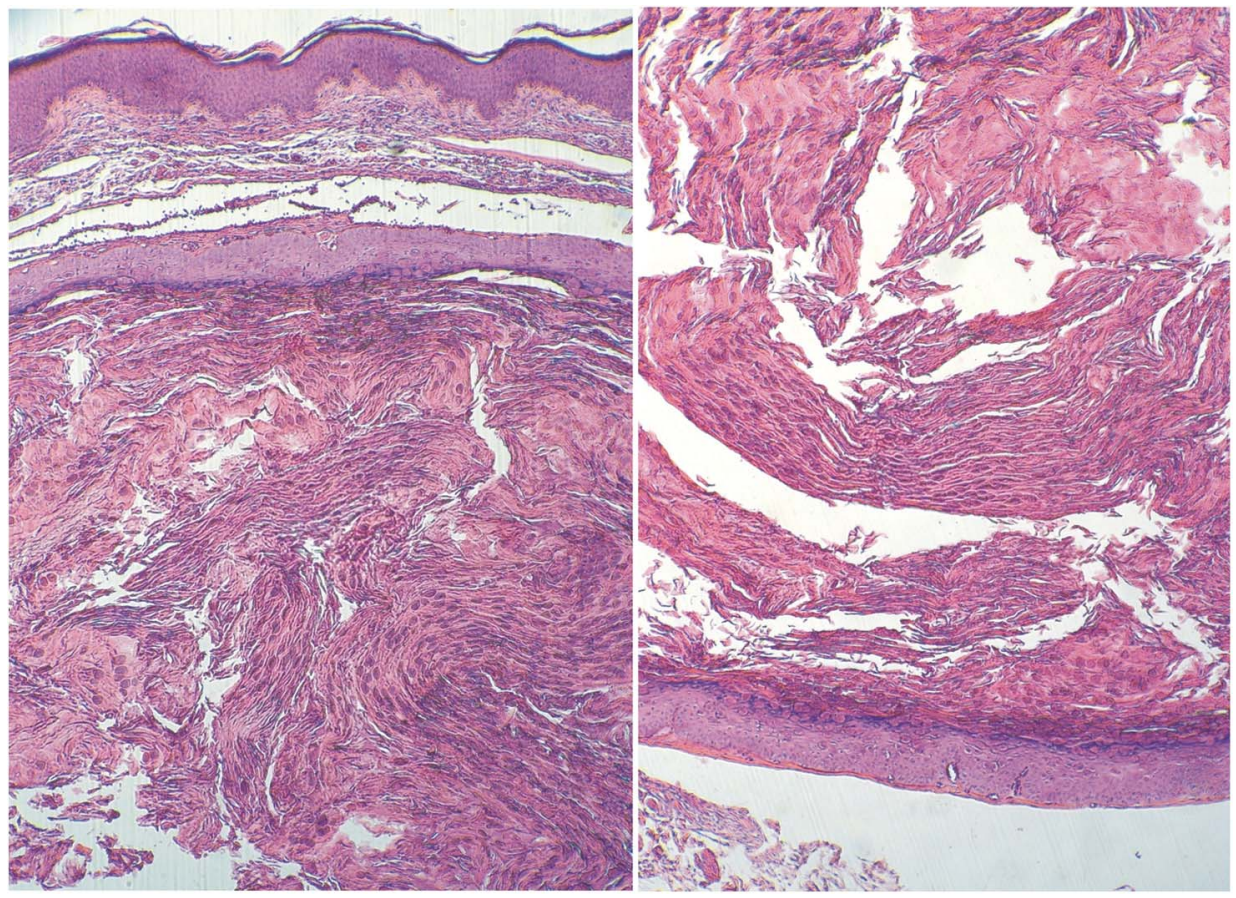

(Am J Dermatopathol 2015;37:908-909)

\section{CASE REPORT}

A 22-year-old healthy man presented to our clinic with a 4-month history of a single, asymptomatic, 1-cm subcutaneous cystic nodule on the pubis.
Histopathologic examination showed a totally normal epidermis. The underlying dermis showed a cystic lesion (Fig. 1) containing many eosinophilic bodies (Fig. 2).

\section{WHAT IS YOUR DIAGNOSIS?}

(Continued on page 949)

\footnotetext{
From the Department of Dermatopathology, Centro Dermatológico Pascua, Buenos Aires, México City.

The authors declare no conflicts of interest.

Reprints: Alberto Ramos-Garibay, MD, Department of Dermatopathology, Centro Dermatológico Pascua, Av Dr. Vertiz 464, Col Buenos Aires 06780, México City, DF. México (e-mail: ramosgari4400@ yahoo.com.mx).

Copyright (C) 2014 Wolters Kluwer Health, Inc. All rights reserved.
}

908 | www.amjdermatopathology.com 
FIGURE 2. Many eosinophilic bodies in the wall and into the cyst (H\&E).

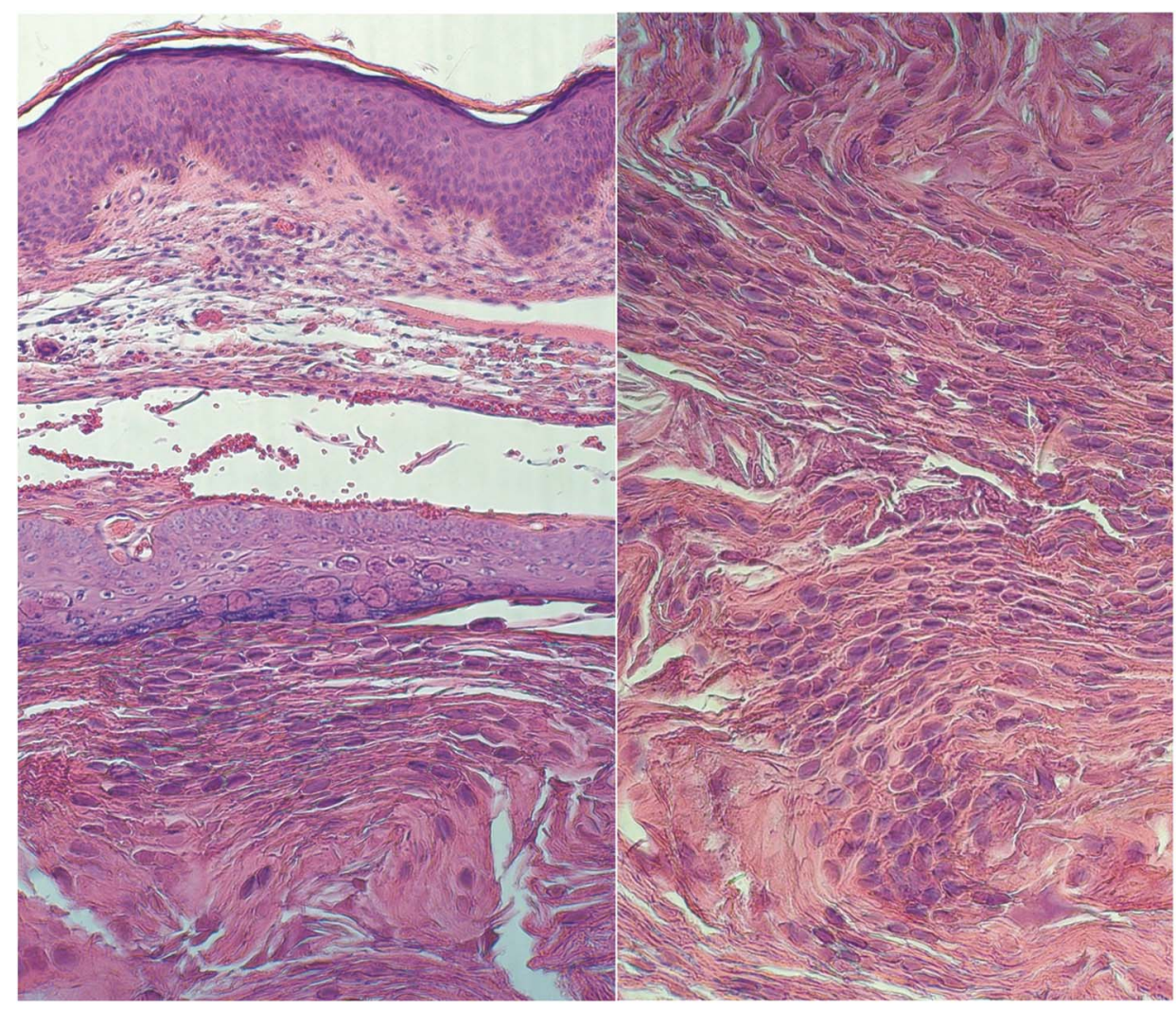

